\title{
La poesía de Leonor de Carvajal y la tradición de los criptojudíos en Nueva España
}

\author{
Michelle M. HAMILTON \\ University of California, Berkeley
}

Entre los documentos inquisitoriales recientemente adquiridos por la Biblioteca Bancroft de la Universidad de California (Berkeley) se incluyen los procesos de Isabel y Leonor de Carvajal, hermanas de otro personaje más conocido, Luis de Carvajal.

Para la vida de Leonor y la de todos los Carvajal las mejores fuentes son la obra de Toro ${ }^{1}$ y la autobiografía de Luis de Carvajal. Esta última obra la forma una serie de escritos de tipo meditativo que Luis incluyó al final de su proceso inquisitorial y en la cual expresa sus extraordinarias y fervientes convicciones religiosas. La publicación de la autobiografía ${ }^{2}$ y su traducción al inglés llevada a cabo por Seymour Liebman ${ }^{3}$ despertaron el interés internacional por el proceso de los Carvajal. Aunque dichas obras centran su estudio en Luis, se puede espigar en ellas abundante información sobre Leonor y sobre los restantes miembros de la familia.

Leonor de Carvajal era la séptima de los nueve hijos de Francisco Rodríguez de Matos y Francisca de Carvajal ${ }^{4}$. Como muchos

\footnotetext{
${ }^{1}$ Alfonso Toro, La familia Carvajal (México, D.F.: Editorial Patria S.A., 1944).

${ }^{2}$ Luis González Obregón y Rodolfo Gómez, Procesos de Luis de Carvajal (el Mozo) (Archivo General de la Nación. publ. 28, México: Talleres Gráficos de la Nación 1935).

${ }^{3}$ Seymour Leibman, The Enlightened: The Writings of Luis de Carvajal, el Mozo (Coral Gables: Univ. of Miami Press, 1967).

${ }^{4}$ TORo Carvajal vol. I pág. 41.
} 
otros inmigrantes, la familia Carvajal llegó a Nueva España a finales del siglo XVI (ca. 1579) en busca de una vida mejor de la que habían tenido en la Península Ibérica. Como judíos que practicaban activamente su religión se vieron forzados a esconder sus creencias religiosas en las tierras católicas de Nueva España. No obstante, las convicciones religiosas de ciertos miembros de la familia eran tan fuertes que su esfuerzo por guardar el sábado y seguir el régimen alimenticio kašer, así como los ayunos que se autoimponían como penitencia por vivir entre los «infieles», les delató ante la Inquisición.

La imagen que emerge en los estudios arriba citados de Luis y de su familia es la de una profunda religiosidad. El hermano habla constantemente en términos religiosos y ve todo-desde lo que come hasta cómo camina la gente en el pasillo- cargado de sentido religioso. Sin embargo, en los folios de su proceso encontramos en Leonor a una persona muy diferente: se puede aseverar que era igual de religiosa que su hermano, pero no había tenido el consuelo de las visiones experimentadas por aquel. Leonor no ha estado «allí arriba», como ella misma dice, y tiene miedo.

Entre los años 1589-1590 la mayoría de los miembros de la familia fueron condenados por judaizantes y encarcelados entre uno o dos años, y también tuvieron que pagar una fuerte multa; finalmente se reconciliaron con la fe católica. Pero a pesar de que los Carvajal aparentemente consintieron en renunciar a su judaísmo, al cabo de cinco años se presentaron nuevas acusaciones contra la familia y en 1595 fueron de nuevo llevados ante la Inquisición.

\section{El SEGUNDO PROCESO DE LEONOR DE CARVAJAL}

La cubierta del segundo proceso de Leonor lleva la fecha de 1595 y la declaración del inquisidor es del miércoles 17 de mayo. Leonor fue apresada y recluida en las prisiones secretas de la Inquisición aquella misma noche. La declaración de los testigos contra Leonor, entregada por escrito a la prisionera, se fue reuniendo en varias audiencias desde el otoño de 1594 al verano de $1595^{5}$. La correspondencia que Leonor y Luis mantuvieron en la

\footnotetext{
${ }^{5}$ El testimonio de Manuel de Lucena está fechado el día jueves, 3 de noviembre de 1594; Isabel Rodríguez de Andrada testificó el jueves, 15 de julio de 1595.
} 
prisión durante los últimos meses de ese año también se incorporó a los materiales del proceso.

El viernes 2 de junio de 1595 tuvo Leonor su audiencia más significativa con los inquisidores. Empezó de la misma manera que las otras: ella aseveraba que no tenía más que decir y, como era habitual, ellos la amonestaban. En esta ocasión cedió y comenzó a testificar contra sí misma y contra su familia y amigos en una confesión que se prolongará durante muchas audiencias y muchos meses, y que constituyó uno de los testimonios más graves y dañinos que obtuvo la Inquisición en Nueva España, contribuyendo de manera sustancial a la acusación de cincuenta y cuatro conocidos criptojudíos.

Leonor involucró a su hermano por el papel que este había desempeñado en persuadirla de que regresara al judaísmo, aparentemente después de que ella se había reconciliado sinceramente con la fe católica en su primer proceso. Su confesión es angustiosa en la manera en que pinta un conflicto de fe tan personal.

Sin embargo, la situación obliga a cuestionar las confesiones hechas por Leonor, quien tenía que saber perfectamente las consecuencias inevitables de ser condenada de nuevo por herejía después de haber recibido ya un «perdón»: ello significaba la pena de muerte. Esto sumado a otros factores -los meses que ya llevaba encarcelada, su miedo a seguir siendo torturada, etc.- hace que cualquier testimonio resulte muy sospechoso. De todos modos, de sus siguientes declaraciones se deduce que desde por lo menos tres años antes del segundo proceso había estado practicando los ritos judíos con su familia.

Al final del proceso ambos hermanos fueron condenados a muerte como herejes lapsos y entregados a las autoridades seculares para que se ejecutara la sentencia. A Leonor, su familia y sus amigos criptojudíos se les dio público garrote y a continuación se quemaron sus cuerpos el sábado 8 de diciembre de 1596. Aquel fue el mayor auto de fe que hasta entonces se había llevado a cabo en Nueva España ${ }^{6}$. En la misma ocasión se condenó como herejes a otros treinta y seis criptojudíos, que recibieron diversos castigos, desde la condena a muerte hasta pasar varios años en galeras o simplemente reconciliarse con la Iglesia ${ }^{\text {? }}$.

\footnotetext{
${ }^{6}$ Martin A. CoHen, The Martyr: The Story of a Secret Jew and the Mexican Inquisition in the Sixteenth Century (Philadelphia: Jewish Publication Society of America, 1973) pág. 253.

${ }^{7}$ COHEN The Martyr pág. 256.
} 


\section{CANCIONES Y POEMAS INCLUIDOS EN EL PROCESO}

Ya sea auténtico o no, el testimonio de Leonor contiene a pesar de todo un muestrario excelente de los ritos y ceremonias que practicaban los criptojudíos de Nueva España. Uno de los rasgos más sobresalientes de esas ceremonias es el uso de canciones y oraciones. Leonor recitó docenas de canciones y poemas a los inquisidores, a veces indicando con detalle el contexto en el cual se interpretaban y también explicando su importancia dentro del sistema de creencias de los anusim. Como sucedió en muchas ocasiones, los inquisidores esperaban que se implicara a sí misma y a otros con sus minuciosas descripciones, pero resulta que esas explicaciones tan detalladas nos permiten conocer los textos de numerosas canciones, que posiblemente provienen de la tradición oral y escrita de las comunidades judías ibéricas de los siglos XV y XVI, restos de los cuales han sobrevivido en la tradición oral hasta este siglo.

Aunque no han recibido mucha atención en los estudios de M. Cohen o S. Leibman ${ }^{8}$, las canciones y textos poéticos que cantaba Leonor y que son de los que nos ocupamos en este estudio forman una parte importante de los textos religiosos que los Carvajal usaban para observar los ritos y ceremonias criptojudías.

El proceso de Leonor aporta datos valiosísimos, no solamente porque proporciona otra perspectiva sobre Luis, sino también porque constituye un testimonio de la importancia que tenían las mujeres de la familia Carvajal en el mantenimiento y transmisión de las creencias judías.

Los procesos de Leonor e Isabel de Carvajal muestran que las mujeres de la familia sabían de memoria muchísimas composiciones poéticas que se utilizaban en las ceremonias y rituales religiosos familiares. Leonor fue quien recitó por primera vez ante la Inquisición las oraciones y canciones del sábado típicas de las comunidades judías españolas y portuguesas de los siglos XV y XVI, que aparecen transcritas en los procesos de todos los Carvajal.

El hecho no debe sorprendernos, dado que en ausencia de un rabino y de cualquier tipo de estructura religiosa organizada, las mujeres del grupo judeoconverso asumieron un papel importante

\footnotetext{
${ }^{8}$ COHEN The Martyr, y LIEBMAN The Enlightened.
} 
en la transmisión de las creencias y de los textos de contenido judío.

Ese papel relevante de las mujeres en la transimisión oral de la fe judía entre los conversos ha salido también a la luz en otros documentos inquisitoriales, como señala Moshe Lazar, quien describe «the women's role as activists in the dissemination of Jewish customs and prayers, and their outstanding courage in proclaiming their faith and accepting martyrdom at the stake ... Even at the time that the Anussim came out from their schizophrenic existence and returned to open Jewish life, Rabbi Yom Tob Zahalon expressed his admiration for the stature and quality, among the Portuguese Anussim, of the women amidst them, "from whom Torah and Judaism shall yet go forth!"» ${ }^{9}$. En su recitar de memoria canción tras canción temas pertinentes a la experiencia de los anusim de Nueva España, Leonor muestra ser depositaria de tal conocimiento judío.

Como los anusim se encontraban con frecuencia aislados y sin acceso a los textos religiosos básicos, recurrían a la memoria para cumplir con sus deberes religiosos lo mejor posible. Lazar mantiene que los propios documentos inquisitoriales han jugado un papel importante en ese proceso de memorización: «they memorized a portable Judaism often transferred from scorched parchments and from inquisitorial sessions» ${ }^{10}$. Así que documentos como los que han sido transmitidos en el proceso de Leonor podían suponer tanto la perdición del interesado como una guía espiritual para otros criptojudíos.

Los poemas y canciones recogidos en el proceso de Leonor de Carvajal, entre los que se cuenta una versión del decálogo en verso, constituyeron pruebas de cargo de consecuencias nefastas para Leonor y su familia. El contenido paralitúrgico judío de esas composiciones con motivos inspirados en el Antiguo Testamento ya era en sí suficiente para despertar sospechas; a ello hay que añadir que en sus declaraciones Leonor explica con todo detalle la forma en que se interpretaban y su función durante el sábado, y asimis-

\footnotetext{
${ }^{9}$ Moshe Lazar, «Scorched Parchments and Tortured Memories: The "Jewishness" of the Anussim», en Cultural Encounters: The Impact of the Inquisition in Spain and the New World, eds. Mary Elizabeth PERRY y Anne J. Cruz (Berkeley: University of California Press 1991) págs. 176-206: pág. 180.

${ }^{10}$ LAZAR «Scorched Parchments» pág. 182.
} 
mo revela a la vez el sentido personal y el importante simbolismo que tenían dentro de su experiencia criptojudía y la de su familia. Todo ello sirvió como prueba de la apostasía de los Carvajal.

Algunos de los textos que Leonor recitó a los inquisidores los usaban los Carvajal en sus ceremonias judías, mientras que otros los había cantado Leonor para animarse a sí misma o a otros durante los meses que pasó en las prisiones secretas de la Inquisición. Cuando se le pidió que aclarase el significado u ocasión de cierto texto, su declaración ofrece un relato íntimo y claro de su función dentro de la familia y de la comunidad, así como de la manera en que se interpretaba.

Obviamente tales textos tenían un significado especial para quien los cantaba o recitaba, contribuyendo a crear un sentido de identidad entre los criptojudíos aislados y perseguidos.

En el proceso de Leonor, que he consultado directamente, aparecen catorce poemas, algunos de ellos completos y de otros al menos una estrofa entera. Como luego veremos, dos de ellos (2.1 y 2.2) no figuran en los procesos de Isabel y Luis, y son estos el único testimonio que tenemos de tales canciones.

Ocupémonos ahora del examen de algunos de estos textos.

\subsection{Canción de queja}

En el proceso de Leonor (fol. $217 \mathrm{v}$ ) aparece el siguiente fragmento de un poema que no figura en los de Luis e Isabel:

Yo dixe con gran dolor,

¡ay!, que en medio de mis días

volví a las puertas sombrías

de esta carçel por mi herror

y por las maldades mías, etc.

Se trata de un fragmento de cinco versos octosílabos cuya rima $a b b a b$ y metro son iguales a los de un ensalmo que recogió Manuel Costa Fontes en la comunidad portuguesa moderna de Canadá ${ }^{11}$ y es semejante en forma a los villancicos peninsulares de principios del siglo XVI ${ }^{12}$.

${ }^{11}$ M. COSTA FONTES, Romanceiro português do Canadá (Coimbra: Actas Universitatis Conimbrigensis, 1980) pág. 485.

${ }^{12}$ Alvar Alonso, Poesía de Cancionero (Madrid: Cátedra, 1991) págs. 373 y 390. 
La situación que dio lugar a que Leonor se refiriera a esta canción ante sus acusadores muestra cómo se identificaba con la voz poética, que regresa a una cárcel oscura al igual que ella había vuelto a las puertas oscuras de las prisiones secretas de la Inquisición.

Explicó Leonor a los inquisidores (fol. 217v) cómo Manuel Gómez Navarro, un correligionario, la había oído por casualidad cantando esa canción y le había pedido que se la enseñara. $\mathrm{Al}$ acceder a ello, le contó Leonor cómo toda su familia estaba encarcelada y que ignoraba quién los había delatado a la Inquisición. Tras tranquilizarla, asegurándole que él no era el denunciante, Manuel informó a Leonor de que su hermano Luis estaba en grilletes. Entonces ella perdió el control y confesó cómo había testificado contra su madre y su hermana, temiéndose que ambas negaran las acusaciones y que las torturasen. La única razón por la cual le contaba todo eso era porque Manuel había quebrantado su juramento de guardar en secreto el asunto.

En este caso la canción crea un lazo emocional entre estos dos criptojudíos, Manuel y Leonor, que se identifican con la desesperación y el terror que expresa la voz poética, y aunque sólo sea un instante, esta canción de soledad ayuda a los dos presos a superar su propia soledad en las prisiones de la Inquisición.

\subsection{Canción de alabanza a Dios}

Veamos ahora otro poema que sólo se encuentra en el proceso de Leonor (fols. 196r-196v):

1 Cantemos con alegría alavanças al Señor; que nayde que en Él confía le a faltado su favor.

2 Cantemos como esperando el sancto rey Josaphat por piedad aguardando en tiempo de adverssidad. La divina Magestad mostró para su loor; que nadie que de Él se fía no le falta su favor. 
3 Estaba un cuento ${ }^{13}$ de gentes $\mathrm{y}$ otras muchas millaradas, que cubrían tierra y mares contra este sancto obediente. Mostró el Omnipotente verdadero defenssor; que nadie que de Él se fía no le falta su favor.

4 Embióle Dios un propheta que a los suyos animasse y que con voluntad recta en Él siempre confiasse, porque sin que peleasse le mostraría el Señor; que a nadie que en Él confía no le falta su favor.

Se trata de un poema de versos octosílabos formado por una cuarteta de rima $a b a b$, cuyos dos últimos versos cumplen la función de estribillo, y tres estrofas de seis versos y rima mayoritaria $a b a b b c$, rimando el último verso con el segundo del estribillo.

Según explicó Leonor la familia cantaba este poema, unos las estrofas y otros coreando el estribillo, y lo acompañaba con baile. Y afirmó explícitamente que el texto subrayaba la necesidad de guardar la ley mosaica, porque el Dios de Moisés es el único en el cual se debe creer, y añadió que ellos -la familia, al participar en el cante y el baile- no creían en la Santísima Trinidad. Parece que Luis cantaba esta canción cuando estaba contento, así que podemos suponer que se entendía como de contenido optimista y de regocijo.

La canción destaca la manera en que Dios recompensa a los que creen en El, y la voz poética se refiere al piadoso rey Josafat a quien Dios, según el relato de 2 Crónicas 20, rescató de la muchedumbre de moabitas y amonitas que le atacaban. Leonor presenta la actuación de esa figura bíblica como un ejemplo de cómo deben comportarse los criptojudíos.

Igual que el primer texto, este también tiene metro y rima comunes a la poesía cancioneril. El estribillo de dos versos, «que

${ }^{13}$ Lusismo 'un millón'. 
nadie que en Él confía / no le falta su favor», se documenta asimismo en oraciones judías modernas de Portugal. Costa Fontes ${ }^{14}$ compara la versión de una oración judía recogida en 1958 por Leite de Vasconcellos (a la derecha) con otra de 1701 recogida en un proceso inquisitorial de Portugal (a la izquierda):

Levantei-me de manhana de manha, ao alvor, Fui rezar os meus salmos ao Senhor.

Quem em esse Deus confia, não lhe faltará favor.

Bendito e glorificado seja o nome do Senhor.
Levantei-me de manhana de manha, ao alvor, a cantar e a rezar sete salmos ao Senhor.

De los dos versos del estribillo del proceso de Leonor, el primero -«que nadie que en Él confía»-difiere algo del verso 5 de las otras dos versiones, aunque expresa la misma idea y es igual la palabra de rima (confía); y el segundo - «no le falta su favor»-, al margen de pequeñas diferencias dado que uno está en español y el otro en portugués, es practicamente igual.

El proceso de Leonor, unos cien años anterior al portugués que encontró Costa Fontes, ofrece la primera muestra de ese estribillo que ha sobrevivido como parte de la tradición oral de los criptojudíos hasta nuestro siglo y constituye un notable ejemplo de preservación de dicha tradición dentro de la comunidad judía.

Costa Fontes cree que la versión que Leite de Vasconcellos recogió y la del proceso de 1701 reflejan dos poemas diferentes, y mantiene que los versos 1-4 constituyen una canción de alabanza y que los versos 5-8 son el principio de otra canción diferente. El propio Costa Fontes ha recogido una versión semejante, en la que esos versos aparecen al principio de un poema independiente que el citado estudioso piensa examinar en el futuro ${ }^{15}$.

La incorporación de esos versos dentro de una alegre canción de alabanza que se acompañaba con palmas parece caber en el

\footnotetext{
${ }^{14} \mathrm{M}$. Costa Fontes, «Four Portuguese Crypto-Jewish Prayers and Their "Inquisitorial" Counterparts", Mediterranean Language Review 6-7 (1993) págs. 67-104: pág. 86.

${ }^{15}$ Costa Fontes «Four Portuguese» pág. 86.
} 
contexto descrito por Leonor, e indica que quizás en su desarrollo dentro de la tradición no se ha modificado el modo de realizar e interpretar la canción.

\subsection{Canción de sábado}

En el proceso de Leonor también aparecen muchos de los textos incluidos en los procesos de Luis e Isabel. Entre los que la familia usaba para celebrar el sábado hay una copla en la que se señala uno de los preceptos obligatorios del día (fol. 69v):

En todas vuestras moradas

fuego no ençendáis

en el sábado que holgáis,

porque serán condemnadas

las almas si tal obráis.

El resultado de violar la prohibición de encender fuego en sábado se plasma aquí en una copla rimada, para que nadie se olvide de sus terribles consecuencias.

\subsection{Cánticos de tema bíblico}

También se versificó el decálogo en una composición que se asemeja a la poesía cancioneril de los siglos XV y XVI. Como complemento de ese poema, se transcribieron en el proceso nueve «cánticos» de tema bíblico. Leonor indica en su testimonio que la familia los cantaba a coro el viernes a la puesta del sol. Su hermano cantaba los cánticos a su madre y a sus hermanas (fol. 123r), y las hermanas que ya los habían memorizado respondían (fol. $125 \mathrm{v}$ ). Leonor dice que su madre sólo escuchaba, porque no se los sabía de memoria. Si por algún razón no podían cantarlos el viernes por la noche, lo hacían el sábado.

En honor del sábado y para honrar a Dios, Luis «dezía» (no leía ni cantaba) la ley de Moisés (vid. texto 2.6.) entera en coplas y las hermanas, pero no la madre, respondían a coro.

Cuando la familia interpretaba esos poemas, Luis solamente dirigía la interpretación pero no era su autor. La propia función de esos poemas dentro de las ceremonias criptojudías de la comunidad así como el hecho de que Leonor jamás haga referencia a 
un autor, limitándose a observar quién había memorizado o no cierto texto, indica que estas composiciones provenían de la tradición oral de los anusim.

El primer cántico, «Si con tanto cuidado cada día», que es el único copiado entero, está formado por seis estrofas de versos endecasílabos, la primera tiene diez versos de rima $A B A B C D E$ $D E E$, y las otras cinco son octavas de rima $A B A B A B C C$ (fols. $123 r-124 r)$ :

\section{Cántico}

1 Si con tanto cuidado cada día cantássemos loores al Señor, como Él tiene de darnos alegría y en todas nuestras cossas su fabor no fueran nuestros males tan continuos, no durara tan grande adverssidad: de sus bienes todos nos hiziera dignos y de poblar su sancta çiudad en la qual fueran largos nuestros años exemptos de peligros y de daños.

2 Confiesso que por ser inobedientes fuimos de nuestra patria deshechados. Vibimos entre incircunçissas gentes con hambres y con guerras afrentados; todos con crueldades diferentes fuimos de nuestra patria desechados. Volbamos al Señor, que Él es piadosso, que Él hará nuestro spíritu gozosso.

3 Cantemos su loor en este día, del Señor escogido y regalado. Ensalçemos su recta y sancta vía, pues sólo a nos lo ha encomendado. De quantas generaciones criado avía tomó la de Ysrrael por mayor grado, multiplicando su generaçión más que las estrellas que en el çielo son.

4 No a de ser en vano la esperança, que no puede faltar lo prometido; 
muy presto gozaremos de vonança si inclinamos a bien nuestro sentido.

Porque aquel que en Dios espera todo alcança, si del bien esperar no es movido. El Señor haga que siempre en Él esperremos y que toda su sancta ley guardemos.

5 Prometido ha el Señor si nos tornamos a la ley de su sancta voluntad y si de coraçón y alma assentamos aver de executar su voluntad. Si con justiçia por fabor clamamos estando en la mayor adverssidad, nos volverá a juntar en esse instante de norte, sur, poniente y de levante.

6 ¿Qué más señal o muestra pretendemos para reconosçer la obligaçión que de sanctificar tal día tenemos con toda alma y todo coraçón? Pues el Señor nos veda que busquemos en él mantenimiento y provisión, gastémoslo cantando los loores del Señor que nos da tantos favores.

Las situaciones que se describen en el poema reflejan la de los Carvajal y en un sentido más amplio la de todos los criptojudíos de Nueva España, España y Portugal. Expulsados de su país natal (vs. 2 b y $2 f$ ), enfrentados al hambre, a las guerras y a diversas crueldades (vs. 2d-e) y viviendo entre los incircuncisos (v. 2c), los criptojudíos se ven a sí mismos como el pueblo escogido, elegidos por Dios sobre todos los otros (vs. $3 \mathrm{~b}$ y $3 \mathrm{~d}$ ). Al enfrentarse a la persecución de la Inquisición y al haber visto a muchos otros criptojudíos asimilarse a la fe católica, esta canción reforzaría sus esperanzas en un porvenir en el que sus hijos y los hijos de la comunidad fueran tan numerosos como las estrellas, «más que las estrellas que en el çielo son» (vs. 3e-h). La canción subraya la necesidad de cantar cada día alabanzas al Señor (vs. 1ab), de reunirse en su nombre (vs. $5 \mathrm{~g}-\mathrm{h}$ ) y de guardar la ley de Moisés (vs. 4 h y $5 \mathrm{a}-\mathrm{b}$ ). 
Los cánticos 2-5 (fols. 124r-124v) no están completos y el escribano dice que sólo trascribió la primera estrofa de cada uno; sin embargo, en el segundo, tercero y cuarto ha anotado al final de algunos versos la palabra «etc.», aunque por el contexto no parece que se hayan omitido versos.

\section{Cántico}

Sí ay razón de estar siempre loando mi lengua al Señor que la ha hecho y con hinnos y psalmos ensalçando al que gobierna el ascondido pecho, etc. Sí ay razón de estar siempre enseñando los que no siguen término derecho. Ella lo sabe bien que lo ha leydo, los ojos muy mejor que lo han sentido, etc.

\section{Cántico}

Sobre mi coraçón tengo esmaltado el nombre del Señor sancto y vendito, etc., y tanto que me siento desmayado en sólo pensar en Él se alegra mi spíritu, etc. Acuérdame del tiempo en que enseñarme fue para libertarme del Egipto y en veer que Él que era entonces es agora espero por momentos mejor ora.

\section{Cántico}

Sobre el más graciosso y alto otero del Monte Raphadí, orando estava el más sancto propheta y el primero, aquél por quien la ley de Dios fue dada, etc. $Y$ en cuanto el valerosso cavallero Jhosué con el enemigo peleava en aquel tiempo Josué vençía quando Moyssén al çielo las manos erguía.

\section{Cántico}

En Garraçí estavan lebantados seis tribus de Ysrrael, que respondían 
con clara voz y a gritos levantados a los levitas que los vendizían. $\mathrm{Y}$ en Eval estavan apartados los otros seys, que a vozes consentían en que fuesse maldito el viviente que a tal señor Dios fuesse inobediente.

Los versos e-h de los cánticos 2 y 3 contienen materia más comprometida que la de la primera estrofa: en el segundo cántico, la idea de ganar prosélitos entre «los que no siguen término derecho"; y en el tercero, el recuerdo de la liberación del Egipto, que parece servir de unión temática entre los cánticos 3 y 4 .

El cuarto cántico (fol. 124v) relata la historia de Moisés -a quien se denomina en $4 \mathrm{c}$ «el más sancto propheta y el primero»- y Josué en Refidim, tomada de Éxodo 17. La escena bíblica nos relata cómo los israelitas no bien han dejado el desierto de Sin donde recibían el maná, sufren el ataque de Amalec. Josué intenta repeler al enemigo y Moisés sube a orar a una colina: mientras mantiene las manos levantadas los israelitas ganan la batalla, pero cuando las baja las tropas de Amalec cobran nuevo ánimo. Moisés, fatigado, se sienta en una roca, y Aarón y Hur le ayudan a mantener los brazos levantados. Tras lograr el triunfo, Dios ordena a Moisés que deje en «el Libro» memoria de lo ocurrido.

Ciertos motivos del poema reflejan los acontecimientos según aparecen narrados en la historia bíblica, como por ejemplo la victoria de Josué motivada porque Moisés consigue mantener las manos alzadas, «al çielo las manos erguía» (v. 4h). Encontramos, pues, en este cántico la supervivencia en la tradición de los criptojudíos de un pasaje bíblico que hace referencia a la cautividad y al regreso de los israelitas a la Tierra Prometida.

El texto del quinto cántico recoge la narración bíblica de Josué 8:30-35, según la cual Josué construye un altar en el monte Ebal, y tal como había mandado Moisés, inscribe sobre las piedras una copia de la ley mosaica en presencia de todas las gentes de Israel, separadas en dos mitades: una frente al monte Guerizim (aquí Garraçí) y otra frente al Ebal.

El tema de la obediencia a Dios (5g-h) se hace eco de la idea de seguir el camino derecho mencionado en el primer cántico. 


\subsection{Canción de súplica}

Otro de los poemas del proceso (fols. 126r-126v) es una canción de 37 versos octosílabos en la que se ruega a Dios que mitigue los sufrimientos. La voz poética se identifica con los huérfanos y las viudas que han sido abandonados y desamparados, y con los que se encuentran en condiciones aún peores, en prisiones severas y aterrorizados por las pruebas y tribulaciones constantes con que se enfrentan:

1 A ti, señor Dios, clamamos con voces y alaridos por vernos tan afligidos: attiende a que desmayamos

5 si no somos socorridos: hollas crianças perdidas, os horfanos desamparados, as biudas afligidas, has donzellas combatidas,

10 os horfãos desamparados $y$ otros peor librados en muy ásperas prissiones y de claridad privados. Con tormentos aleyjados

15 y con ásperas prissiones, andan nuestros coraçones tan cobardes de temor das continuas afliçiones y fortes tribulaçiones,

20 que esqueyçemos tu amor ${ }^{16}$. No nos tarde el tu fabor, señor Dios del firmamento; da remedio a nosso door ${ }^{17}$. Apláquesse el tu furor

25 per tuo prometimiento, no te lembre nos os erros 18 pues a ti nos convertimos;

${ }^{16}$ Lusismo 'que se nos olvida tu amor'.

${ }^{17}$ Lusismo 'dolor'.

${ }^{18}$ Lusismo 'no te acuerdes de nuestros errores'. 
que aynda que te erramos mutas vezes cada día,

30 por Señor te confessamos $y$ tu nombre invocamos siempre de noche'y de día. Péssanos de aver peccado, mas haremos penitençia;

35 no mires a lo passado, ussa, Señor, de clemençia como siempre as acostumbrado.

\subsection{El decálogo}

Uno de los textos más interesantes en el proceso de Leonor es la «Ley de Moisés» (fols. 126r-127v), larga composición de sesenta y un versos, agrupados en doce estrofas de cinco versos octosílabos (la 12 con seis), cuya forma poética facilitaría sin duda la memorización de los diez mandamientos dados por Dios a Moisés.

La primera estrofa parece estar toda ella en español, mientras que los elementos portugueses ya son evidentes en el segundo verso de la segunda estrofa (meu acatamento). En el resto del poema continúa esa fluctuación entre el español y el portugués, con cierta tendencia hacia esta última lengua, lo que sugiere que quizás el escribano estuviera intentando transcribir en español un poema que Leonor recitaba en portugués.

Aquí comiençan los mandamientos de la ley de Moyssen:

1 Yo soy tu Dios y Señor, que con poder infinito te liberté del Egipto donde vibías con dolor y ásperamente aflito.

2 No tendrás dioses agenos ante meu acatamento, ni farás alguos tropheos semellança dos arreos con que horné o firmamiento.

3 Nada desto adorarás ni les darrás algún honor; 
a mí so por Dios tendrás que soy fuerte zelador en quantas cosas verás.

4 Meu nome no jurarás sobre alguna vanidad sin muta necessidad; bien castigado serás si fizieres tal maldad.

5 Lémbrate sanctificar a meu día señalado: os seys podes travallar en lo que mais te agradar; ho séptimo te he vedado.

6 Porque en seis días crieu todas has cosas criadas, en el séptimo descansé: por esso santifiqué, seguirás suas pissadas.

7 Tu pay y may honrrarás y vivirás largamente, siempre alegre y contento hea terra que posseerás por mano do Omnipotente.

8 Fuge da alguien matar, guarte da fornicaçión, $\mathrm{y}$ de alleno furtar y ao próximo lebantar testimonio de trayçión.

9 Não deseges cossa agena, ni tampoco ha mulher, ni hao esclavo que tuviere, boy o asno; cossa fea la qual o Señor não quere.

10 Todo o poblo oveu las vozes del poderosso Señor; de ante su grande resplandor 
y de las más cosas que oveo

se apartó con gran temor.

11 Todos a Moyssén dixeron que él se les relatasse ho que ho Señor le mandasse, que elhes obedeçerían temendo que hos matasse.

12 Él le dije: «Não temáis, que esto fez nosso Señor para vos provar no mais si de Él tendes temor vindo y a tantas siñaes feytas en vosso fabor», etc.

La voz poética del texto es la de Dios hablando a Moisés y al pueblo de Israel, y las estrofas 1-9 siguen muy de cerca la formulación del decálogo en Éxodo 20:2-17. No he encontrado, sin embargo, en la tradición judeoconversa otro ejemplo en el que Dios se dirija al pueblo, aunque en algunos de los romances que Costa Fontes ha recogido los que hablan son Jesús o la Virgen ${ }^{19}$.

A partir de la estrofa 10 el poema sigue narrando lo que se dice en Exodo 20:18 y siguientes: cómo los israelitas, asustados ante el resplandor y las voces, temen la muerte y piden a Moisés que les sirva de intermediario y cómo Moisés les tranquiliza, explicándoles que Dios lo ha hecho sólo para probarlos. Quizá el contenido de la estrofa 12, aunque su texto está directamente inspirado en el bíblico, tuviera para los criptojudíos una segunda lectura: la de que la adversidad es tan sólo una prueba, o lo que es lo mismo, si los israelitas habían salido de la adversidad de Egipto, también lo harían los criptojudíos sometidos a prueba en Nueva España.

El proceso de Leonor documenta los salmos, coplas, canciones y poemas que la familia Carvajal usaba como parte de sus ceremonias religiosas y también como fuente de consuelo durante su aislamiento en Nueva España y su encarcelación por la Inquisición. Es interesante que el testimonio de Leonor sobre la manera

${ }^{19}$ M. Costa Fontes, Romanceiro português dos Estados Unidos II: Califórnia (Coimbra: Actas Universitatis Conimbrigensis, 1983) págs. 186-187, y Romanceiro português do Canadá pág. 244. 
en la que los miembros de la familia practicaban juntos su judaísmo resulta ser la prueba más dañina de los procesos de 1595-1596.

Esos textos eran la base de la fe de los Carvajal y dan una idea razonablemente exacta de las costumbres criptojudías del siglo XVI en Nueva España. Además de su valor antropológico y sociológico, esos fragmentos nos ofrecen también una visión de la tradición oral de los criptojudíos, a la que se incorporaron elementos de la cultura dominante de Nueva España y también otros tradicionales que se remontan a los orígenes portugueses de la familia.

\section{RESUMEN}

Entre los documentos inquisitoriales de Nueva España recientemente adquiridos por la Biblioteca Bancroft de la Universidad de California (Berkeley) se incluye el proceso de Leonor de Carvajal, hermana del mejor conocido Luis de Carvajal. En el transcurso del proceso afloraron canciones y poemas, e incluso una versión del decálogo en verso, que constituyeron pruebas de la herejía de la familia. En este estudio se examina una serie de textos, algunos publicados aquí por primera vez, y se interpretan a la luz del contexto histórico, subrayando su papel dentro de la tradición oral de los criptojudios en el mundo hispánico.

\section{SUMMARY}

Among the Inquisition documents recently acquired by the Bancroft Library, University of California, Berkeley, is the trial of Leonor de Carvajal, sister of the more famous Luis de Carvajal. The songs and poems recorded in Leonor de Carvajal's trial, including a version of the Mosaic Law in verse, proved to be damning evidence against Leonor and the rest of the family. This study examines several texts, some of which are published here for the first time, taking into account their historical context and underscoring their importance in the CryptoJewish oral tradition. 